\title{
elyra
}

\section{Ao vivo: performance da voz em Tarkos e Aperghis}

\author{
Annita Costa Malufe \\ $P U C-S P / C N P q$
}

Silvio Ferraz

$U S P / C N P q$

Resumo: Neste artigo tratamos da noção de performatividade poética em relação às propostas de Christophe Tarkos e Georges Aperghis, tendo em vista a presença do que chamamos de "hábitos de fala", na construção das vocalidades típicas de seus textos. Como pressuposto para nossas reflexões está o conceito de performance trazido pelo teórico e medievalista Paul Zumthor e sua relação intrínseca com a presença da voz e de uma temporalidade específica: o "tempo real" que caracteriza a experiência da leitura poética concebida enquanto performance, e que aqui denomina-se por "ao vivo". Distinguimos assim as diferentes músicas da fala criadas pelos autores, a partir de operações singulares de cada um com os "hábitos de fala" e seus respectivos envelopes sonoros. Trata-se de ressaltar a presença desse "ao vivo" e do tempo irreversível, nas poéticas de Tarkos e Aperghis, com exemplificações a partir de seus escritos.

Palavras-chave: Poética, Performance, Vocalidade, Christophe Tarkos, Georges Aperghis

Abstract: In this article, we deal with the notion of performativity in relation to the proposals of Christophe Tarkos e Georges Aperghis. We consider here the presence of what we call "speech habits" in the construction of the vocalities in their texts. The Paul Zumthor's concept of performance is our presuppose, in its relation with de voice presence and its specific temporality: the "real time" which characterizes the poetic lecture experience conceived as performance, that here we call "live". We intent to distinguish the different types of "speech music" by the authors, created from particular operations with their "speech acts" and their respective 
sound envelopes. Its about highlight the presence of that concept of "live" and the irreversible time in Tarkos and Aperghis poetics, bringing examples of their writings.

Keywords: Poetic, Performance, Vocality, Christophe Tarkos, Georges Aperghis

Pretendemos colocar em diálogo duas poéticas que nos parecem exemplares acerca do acoplamento poesia e performance na contemporaneidade. Um poeta, o francês Christophe Tarkos (1963-2004), e um compositor, diretor teatral e também poeta, o grego radicado na França, Georges Aperghis (1945-), que têm em comum o trabalho intenso com o material vocal. Em ambos, a voz é entendida como terreno de intersecção entre os campos da música, do teatro e do poema. A voz como intermodulação entre palavra, som e corpo, enfatizando a natureza performática da experiência poética.

Quando pensamos aqui nesta performatividade própria à experiência dita "poética", temos em vista sobretudo os estudos de Paul Zumthor. Medievalista que, ao se dedicar à pesquisa da poesia oral, chegou a um conceito operativo acerca da performance, estendendo-o para além do contexto da poesia medieval. Se em Zumthor podemos falar em uma performance ligada à leitura do texto poético é porque, para ele, a leitura propriamente poética é aquela que assim se define por colocar em jogo o corpo daquele que lê. "Que um texto seja reconhecido por poético (literário) ou não depende do sentimento que nosso corpo tem" (Zumthor 2005: 41). É, ainda, porque a voz desse corpo se faz ouvir na poesia, mesmo se lida em silêncio: voz que remete aos corpos e seus afetos. A poesia é, neste sentido, mais voz do que palavra - ou só é palavra na medida em que é voz: a voz enquanto algo que está aquém e além da linguagem: "a voz ultrapassa a palavra", diz Zumthor (1997: 13), é uma "coisa" concreta, lugar das sensações do corpo e de sua intrincada relação com a linguagem verbal.

De modo que essa voz precisa "acontecer" a cada vez, em cada leitor, em um "tempo real" que é próprio do corpo, como diz Zumthor: "O tempo da poesia oral é corporalizado. É um tempo vivido no corpo: aquilo que denomino um tempo real" (Zumthor 2005: 83). Há um "aqui agora" na performance que é o "aqui agora" que define a experiência poética 
enquanto a imersão do corpo em um novo espaço-tempo. Um "ao vivo" que envolve todos os corpos concretos em jogo em um determinado campo de forças: “A performance é a ação complexa pela qual uma mensagem poética é simultaneamente, aqui e agora, transmitida e percebida. Locutor, destinatários e circunstâncias (...) se encontram concretamente confrontados" (Zumthor 1997: 33).

Este ponto de vista acerca da performance, do qual partimos, permite-nos estendê-la em direção a um conceito que não se limita ao gênero artístico performance, ainda que tome dele muitos de seus aspectos, e tampouco restringe-se à poesia lida em uma audição pública ou produzida exclusivamente para ela. Ponto que vale salientar uma vez que, nos casos aqui escolhidos, trata-se de dois autores e poetas que, de um ou de outro modo, incluíram a prática da performance e o uso da voz propriamente dita em suas trajetórias artísticas. Tarkos, improvisando poemas em leituras públicas, nas quais às vezes convidava amigos, às vezes lia em parceria com instrumentos musicais, tendo gravado algumas leituras às quais hoje podemos ter acesso em CD. E Aperghis, trabalhando com aquilo que chama de teatro musical, e compondo peças para voz a partir de poemas que funcionam como partituras para espetáculos que se situam nessa fronteira entre o teatro e a música - e que podem muito bem encaixar-se no gênero mais amplo e híbrido da performance, inclusive com amplo uso de tecnologias eletrônicas.

Entretanto, trata-se de destacar aqui sobretudo a potência performática presente nos textos de ambos os autores como a emergência de um pensamento performático da própria escrita. Em ambos os casos, ela se dá a partir do trabalho com uma vocalidade do poema, que se sobrepõe à linguagem verbal, restrita às camadas linguísticas. Estamos diante de vocalidades singulares, e da experiência poética pensada e composta enquanto trabalho com essa voz do corpo, muito próxima à concepção de Zumthor.

Em cada um, Tarkos e Aperghis, uma criação diversa de máquinas vocais, com seus funcionamentos particulares.

Em Tarkos, a escrita tomada em um fluxo contínuo vocal. As palavras são trabalhadas em um jogo de reiteração direta, sem pausa, em uma espiral que se expande a partir de um centro provisório, mas sempre tendo em vista algum centro: palavras ou frases ímã, como pontos de gênese dos ciclos: 
Quel est le flux, quel est le flux qui rencontre un obstacle, quel est ce flux, le flux rencontre un obstacle, quel est ce flux qui rencontre un obstacle le flux rencontre plus d'un obstacle, le flux a vu un obstacle par l'obstacle duquel le flux a vu l'obstacle, le flux a voulu aller vers l'obstacle qu'il a vu, voilà un flux qui vient à la rencontre d'un obstacle, les flux viennent à leur rencontre, l'obstacle allait vers les flux, des flux ont vu plus d'un obstacle, quel est le flux, le flux va rencontrer un obstacle qui rencontre des flux, des flux viennent à la rencontre d'un obstacle, l'obstacle attend de voir venir le flux, les flux vont à la rencontre d'obstacles, les flux passent à travers les obstacles, quel est le flux, le flux rencontre des obstacles, le flux attend de rencontrer un obstacle, des nombreux obstacles sont dans les flux, les obstacles arrivent dans le flux, quel est le flux, un flux rencontre un obstacle lequel a vu des flux, le flux vient chercher un obstacle, les obstacles passent les flux, le flux vient sur un obstacle, les flux rencontrent plus d'un obstacle, le flux va à la rencontre d'obstacles à rencontrer des flux, l'obstacle a plus d'un flux, l'obstacle passe dans le flux, un obstacle rencontre les flux, un flux et un obstacle se rencontrent. (Tarkos 1998: 25) ${ }^{1}$

Em Aperghis, palavras ou fonemas em fluxos vocais truncados. Muitas vezes, uma escrita em língua indecifrável, como se brincasse com as sonoridades das línguas estrangeiras ou mesmo do francês, explorando apenas sons dos fonemas e consoantes, de modo próximo ao dos poemas fonéticos dadaístas e futuristas - como vemos nas anotações intituladas "Fonemas", nas quais reflete sobre tipos de combinações entre consoantes e vogais:

(Ancestral unicelular, vogais e consoantes em igualdade)

VI ïn fa oü av éë hf no lh uï

Oö vf nu uà ié lv el hn fi ah

Lé ol vn aïho fh uü éf na iv [...]

(Ornamentações-percussões)

utsoa siéti éstan sédaé tanad tadou isdié odtia duödo adisu ododo ad ou utéti tiaïs dutia ésisu todaé sésué sisoa intan odota isisu todié adéti dousé éstan dusué tadaé ésdou odsoa [...] (Aperghis 2001: 73)

Ou jogando com um procedimento simples de truncar o fluxo a partir de rupturas de frases e acréscimos paulatinos de termos: 
CONVERSATION

Suis celui

Suis celui suis

Suis celui suis celui

Suis celui suis celui qui

Suis celui suis celui qui suis

Suis celui suis celui qui suis celui

Suis celui suis celui qui suis celui qui

Suis celui suis celui qui suis celui qui vient

Suis celui suis celui qui suis celui qui vient suis

Suis celui suis celui qui suis celui qui vient suis celui

Suis celui suis celui qui suis celui qui vient suis celui qui

Suis celui suis celui qui suis celui qui vient suis celui qui vient [...] (Aperghis 2004 : 65)

Nas criações poéticas de Tarkos e Aperghis a voz falada é explorada de modos diversos para produzir sons, ritmos, sentidos, criando diferentes tipos de músicas da fala. Há, em ambos, uma espécie de obsessão por modos de falar, por musicalidades, entonações, jeitos e gestos da voz falada. Obsessão que aparece em Tarkos, como bem define Christian Prigent, como um "puro prazer de falar, um prazer quase infantil de deixar correr o fluxo do balbucio" (Tarkos 2008: 16, tradução nossa), e faz com que, em nossa leitura, mergulhemos nesse fluxo elocutório. E, em Aperghis, pela exploração exaustiva de "maneiras de falar", como ele mesmo diz, às quais ele sempre foi "muito atento", a tal ponto que mesmo suas composições para os instrumentos se baseiam na "transposição dessas maneiras de falar" (Aperghis 2001: 21). É interessante notar como sua pesquisa musical é centrada nessas maneiras, explorando-as tanto através das rubricas, quanto através da própria escrita a partir de fonemas, que se articulam criando línguas novas e simulando até sotaques e dialetos.

\section{Envelopes sonoros}

A presença marcante dos procedimentos de repetição e permutação, em ambos, parece ir na direção dessa busca por uma música da fala. Mas, ainda que aparentemente similares, tais procedimentos são utilizados diferentemente em cada um, provocando 
diferentes efeitos. Denominaremos aqui por "hábitos de fala" esses modos específicos através dos quais cada autor agencia suas máquinas de voz, refletindo a marca forte das poéticas em que a vocalidade é central como aquela de Samuel Beckett, grande referência para ambos autores, ou ainda a música vocal de Luciano Berio e a prática de outros poetas que fizeram da fala seu material privilegiado, como Bernard Heidsieck ou Ghérasim Luca. Em outro artigo, trouxemos a noção de envelopes sonoros, que condensariam esses hábitos de fala. $^{2}$ Noção que vale retomar acerca das escritas de Tarkos e Aperghis, nas quais a vocalidade constrói, para cada caso, um tipo de envelope sonoro, como efeito de diferentes estratégias construtivas de escrita - ainda que, no palco, no corpo e na voz literalmente presentes, elas ganhem por certo novas dimensões, que não entrarão no escopo do presente artigo. ${ }^{3}$

Ao pensarmos em hábitos de fala, temos de notar primeiramente que eles estão sempre ligados ao corpo em que essa fala se dá, aos gestos de uma boca, ou mesmo a todo um corpo, que emite a voz. Cada pessoa possui seus próprios modos habituais de escolher palavras e de ligar essas palavras entre si e, ainda, de lhes imprimir uma determinada velocidade, de fazer as pausas, as retomadas etc. Nesse sentido, a fala pode ser vista como uma máquina não apenas de produção sonora específica, mas máquina em que os sons que produz se constituem dentro de alguns padrões de fluxo. Padrões que evitam certas construções e favorecem outras. Tais hábitos da fala são determinados por fatores totalmente distantes do pensamento escrito, implicam formato e musculatura facial, hábitos de significação, hábitos culturais e familiares, velocidades de fala e de conexão de imagens, hábitos e características respiratórias, posturais, gestuais, de expressão, etc. Um sem número de fatores dificilmente mapeáveis mas facilmente identificáveis como diferenças marcantes no modo de cada pessoa falar - tanto mais se comparamos pessoas de diferentes línguas e culturas, ou de diferentes gerações, por exemplo. ${ }^{4}$

A partir dessa ideia, pode-se pensar que cada conjunto de hábitos de fala, mais ou menos estáveis, cria padrões, que podem ser "envelopados", pensados conjuntamente, enquanto certa textura particular (de velocidades, gestos, recorrências...). Teríamos aí diferentes "envelopes sonoros", aglutinando hábitos de fala distintos; cada envelope com um mecanismo interno que é um modo especifico de escolher, ligar e permutar palavras. De 
modo que tais máquinas de fala podem ser também entendidas como máquinas de criação de línguas novas. Partiríamos aqui do pressuposto de que em cada fala haveria uma nova língua se criando, um novo sistema linguístico. O que se faz pertinente no pensamento mais amplo da filosofia de Gilles Deleuze, em que a distinção da linguística entre o sistema geral da língua e o uso específico na fala não faz sentido. A fala poética define-se justamente por isto, por coincidir com a língua, ou por criar uma língua nova, diz Deleuze, o que vemos desenvolvido de modo mais explícito em Crítica e clínica, quando nos diz, referindo-se aos conceitos saussurianos de "fala" e "língua", que a fala poética é aquela em que a língua se confunde com a fala, justamente por seu potencial de variação e heterogênese, que faz operar um funcionamento típico do que seria o sistema da língua. ${ }^{5} \mathrm{~A}$ poesia é criação de língua, aliás, a literatura o é de modo geral para Deleuze, uma vez que ela cria o próprio sistema no qual ela irá se dar, num movimento de autopoiesis.

Assim a ideia desses envelopes sonoros, agregando conjuntos metaestáveis de hábitos de fala, nos permite imaginar a constituição dessas diferentes línguas, em cada um desses poetas. A voz nas composições poéticas de Tarkos e Aperghis sendo um envelope sonoro, que traz em si um mecanismo interno singular, uma língua nova, a partir de gestos típicos de cada uma de suas máquinas vocais. São formas diversas de musicalidade provenientes desses mecanismos específicos de cada um dos autores. Neste sentido é que podemos pensar nas duas práticas aí presentes, tendo os dois gestos básicos que diferenciam o tipo de fluxo vocal predominante em cada um: 1. o fluxo de continuidade (Tarkos) e 2. o fluxo forçado (Aperghis).

Desdobrando o que trouxemos acima, nos exemplos rápidos que demos de dois autores: em Tarkos, temos um fluxo de continuidade: um fluxo próprio de construções frásicas em que a reiteração de palavras e sonoridades segue um fluxo cotidiano, em frases de construções ordinárias:

Je me peigne. J'ai mon peigne, je suis peigné maintenant, je me suis peigné, je n'étais pas bien peigné, je sais me peigner, j'ai bien peigné, je me suis peigné, j’ai bien fait de me peigner, je suis bien peigné maintenant je pense, je pense je me suis assez peigné maintenant. J'avais à me peigner. Peut-être devrais-je me peigner. (Tarkos 1995: 42) 
[Eu me penteio. Eu tenho meu pente, eu estou penteado agora, eu me penteei, eu não estava bem penteado, eu sei me pentear, eu me penteei bem, eu me penteei, eu fiz bem de me pentear, eu estou bem penteado agora eu penso, eu penso eu estou um tanto penteado agora. Eu tinha de me pentear. Talvez eu deveria me pentear. (Trad. nossa).]

Neste exemplo, muitas vezes é a vírgula, ligando as frases por coordenação, que funciona como elemento de continuidade, de "liga", entre os fragmentos - que geralmente são orações, e não palavras sozinhas, como no caso de Aperghis. Os fragmentos nos fluxos de Tarkos costumam ser maiores, grupos inteiros de palavras (frases ou orações) que são agenciados de modo a criarem continuidade entre si - ainda que não se trate de uma continuidade "lógica" ou de "significação", vale atentar. Pois reside nisso um dos paradoxos de seu funcionamento: criar falsas continuidades, falsas linearidades de significação. E, poderíamos dizer até, falsas banalidades ou simplicidades de conteúdo. Ao lado das frases que parecem obedecer construções sintáticas ordinárias, contrastam-se os sutis deslocamentos semânticos, que desmontam uma fala comum, ainda que esta seja sempre o material bruto do poeta.

Como observa o poeta e crítico Christian Prigent, no prefácio a Écrits poétiques de Tarkos, esses textos são apenas aparentemente descritivos; partem de simples descrições ou narrações do cotidiano como meros pretextos, estratégias para desfazer sutilmente a figuratividade da linguagem. O que está em jogo não é a função de foto ou representação, mas ao contrário, o jogo com o material da palavra, ou a palavra enquanto material plástico, moldável, em seus jogos internos de velocidades, retomadas, acelerações e ralentadas, pausas, circunvoluções. Bastante do que defenderá Tarkos em diversos lugares, como na entrevista a Bertran Verdier, no mesmo livro: "O texto não serve a algo, ele é algo. A cada vez o que me incomoda é de se esquecer a materialidade do texto. Há verdade no texto, é tudo, a verdade palpável da existência material do texto" (Tarkos 2008 : 358-359). Ao final, como bem diz Prigent em seu prefácio, trata-se de um ritmo, da provocação por uma velocidade da leitura: "A aceleração da sintaxe leva o todo a uma irresistível velocidade" (idem: 15).

Para provocar esse devir-fala da escrita, essa tomada de assalto da escrita pelo movimento da voz, nada mais adequado do que o uso de expressões e temas banais, que 
não coloquem verdadeiramente "problemas" para a leitura. O leitor rapidamente sente que não é naquilo está sendo tratado que reside a questão chave dessa poética (a ação simples de se pentear, por exemplo). Trata-se de algo mais, e para além da designação e da significação. É preciso assim deixar-se contaminar pelo fluxo contínuo que se cria no encadeamento dessas frases simples, apenas aparentemente descritivas.

Já em Aperghis, falamos em um fluxo truncado pois é aquele que desfaz a linearidade da fala, a partir de procedimentos que desmontam a sintaxe corriqueira de modo explícito. Muitas vezes associando os procedimentos de desmontagens de palavras e de permutação, esse fluxo também marcado por repetições é um fluxo, no entanto, de truncamentos, como que traindo alguns hábitos corriqueiros de fala para abrir espaço a outros:

\section{SANS TITRE (2)}

(diction très rapide, accentuer les " fini »)

Fini par-à-part elle bitue par ni bituer-fin elle a a fini

elle par fini s'habituer tuer

Elle a a a par fini par fini par par elle fini s'habituer // a ni elle fin

s'habituer fini s'habituer tuer par à //

Elle ni fini fin elle par-à-par fini elle s'habituer fini

s'habituer s'habituer // par tuer elle a a a

Fini par par à s'habituer elle s'habituer elle s'habituer à part par fini elle par à tuer fini s'habituer à ni elle fin

Par elle elle a a fini fini par par tuer s'habituer par s'habituer par s'habituer à elle ni fini // fin à s'habituer

Elle tuer par s'habituer s'habituer ni s'habituer fin elle par à elle fini-fini a a fini part-part

A fini-fini tuer fini // à à s'habituer elle ni par fin // elle elle par à s'habituer // par s'habituer par //

À fin elle fini a tuer fini à s'habituer à part s'habituer fini ni s'habituer par par elle elle S'habituer s'habituer // s'habituer ni par fin elle tuer a a fini à part par-par // elle part à elle fini-fini // S'habituer à s'habituer elle par a elle fini a part fini tuer par à fin elle s'habituer fini -ni (Aperghis 2001: 68-69) 
A impressão que podemos ter nesse texto, parte do espetáculo Machinations, é a de uma fala de hesitações, de gaguejamentos ("a a a "; "elle elle"; "par par"; mas também em ecos: "s'habituer tuer" "fini-fini tuer fini" etc.) - para evocar o termo explorado por Deleuze, e retomado pelo próprio Aperghis, ao referir-se a autores como Beckett e Ghérasim Luca, em Crítica e clínica. Deleuze fala em gagueira criadora para definir alguns procedimentos de repetição que se inserem na base da criação de uma língua poética. O procedimento de Aperghis, acima, remete-nos ao de poemas de Luca que faz derivar da repetição de fonemas a montagem de palavras com sons similares. O que Luca faria em seu poema "Passionémment", segundo Deleuze (1993: 139), é expor a gênese de uma língua nascente, que progride por repetições, de fonemas, por derivações de palavras homófonas, como se a voz fizesse um tateamento entre sons, em busca de compor um sentido. No caso acima, de Aperghis, o quadro de palavras é mais restrito, porém, vemos algo desse tateamento entre palavras e fonemas ("bitue", "bituer", "habituer", "tuer"; "part", "par"; "fini", "ni") que vai criando uma língua estranha, inédita.

Se imaginássemos que esta é a fala de alguém - e efetivamente no palco uma das "diseuses" 6 pronuncia esse texto, conforme as indicações de Aperghis ("dicção muito rápida, acentuar os "fini") - podemos ter a sensação de uma fala aflita, ou maníaca, com algum desajuste. Um conjunto de manias, vícios, ou hábitos, faz-se presente aqui. A partir desses, que nomeamos por hábitos de fala, um envelope sonoro é criado, uma espécie de textura específica, que é também uma textura de gestos - de certos tipos de reiteração e permutação - e de velocidades, provocadas por tal arranjo de fonemas e palavras. Os sons permutados, neste caso, criam um movimento circular, de palavras que fazem o texto "proliferar pelo meio", como o próprio poeta e compositor descreve: "Eu tinha em mente também aquilo que diz Deleuze sobre a geração pelo meio, mais do que pelo fim ou pelo começo. Algo como um vulcão que irrompe e do qual a cratera ou a fenda se estende." (Aperghis 2001: 59).

Em uma de suas Récitations, peças escritas para voz solo, explorando músicas da fala, a partir de diferentes envelopes sonoros, podemos ter um exemplo desse crescimento pelo meio; trata-se do trecho do texto da "Récitation 11", que inserimos na tabela abaixo, que não está na partitura original de Aperghis, para explicitar essa dinâmica: 


\begin{tabular}{|l|l|l|}
\hline$[\mathrm{A}]$ & Comme ça & {$[\mathrm{B}]$} \\
\hline Faut pas vous appeller & comme ça & va-lui demander toi \\
\hline C'en est un faut pas vous appeller & comme ça & va-lui demander toi et puis? \\
\hline Je m'excuse c'en est un faut pas vous appeller & comme ça & va-lui demander toi et puis? Gramme \\
\hline $\begin{array}{l}\text { Je veux que Je m'excuse c'en est un faut pas vous } \\
\text { appeller }\end{array}$ & $\begin{array}{l}\text { comme ça } \\
\text { va-lui demander toi et puis? Gramme par } \\
\text { gramme [... }\}\end{array}$ \\
\hline
\end{tabular}

(Aperghis 1982: “Récitation 11", grifos e diagramação nossos.)

A repetição da expressão "comme ça" (assim ou desse modo) cria um eixo, a palavra ou frase ímã a que referimos anteriormente, em torno do qual as orações se engancham e se chamam umas às outras. Orações simples do cotidiano, ligadas por essa expressão que parece servir de elo de ligação entre duas vozes em confronto, começando com o mote primário que sofrerá acréscimos paulatinos: "Faut pas vous appeller comme ça va-lui demander toi" ("não é preciso vos chamar assim ele que vá pedir a ti"). Sem sabermos no entanto, e não parece vir ao caso, quem são as personagens que aqui dialogam, tampouco se há apenas uma personagem na qual interagem vozes equívocas, nota-se que na segunda parte de cada linha (coluna "B), após o retorno do eixo "comme ça" o "vous" da primeira parte (coluna " $A$ ") se torna "tu", o que sugere haver mais de uma voz ou, ainda, mais de um interlocutor, em jogo. O eixo central servirá também de pausa, de transição entre essas quase-vozes que se mesclam.

E, a partir da segunda linha, essa primeira célula mote "Faut pas vous appeller comme ça vá-lui demander toi" começará a crescer (ver os grifos) do seguinte modo: as primeiras partes das frases (coluna "A") a partir de acréscimos de palavras no seu início: "C'en est un faut pas vous appeller" (soma-se o "c'en est un", célula que desse modo é apenas um fragmento, funcionando como fonemas soltos que sintaticamente não compõem sentido); para depois acrescentar-se "je m'excuse" (peço desculpas): Je m'excuse c'en est un faut pas vous appeller", mas que ainda não dá o sentido completo dos fonemas acrescidos. Até que a frase vai lentamente se formando e ganhando sentido e refazendo a sintaxe, com as somas paulatinas. E na segunda (coluna "B") a oração irá crescer desse mesmo modo mas por acréscimo de palavras ao seu final: "va-lui demander toi et puis?"; em seguida: "va-lui demander toi et puis? Gramme", e assim por diante. Conforme veremos, esse acréscimo colocado em loop, criando um movimento cíclico em que as frases acabam crescendo pelo meio, como ele diz, é um procedimento recorrente em Aperghis, seu modo de criar um 
tempo que vai crescendo e tornando sensível o seu desenrolar. Trata-se de um modo de compor envelopes sonoros que dão a sensação de avançar, por tropeços da fala, em um fluxo vocal em uma espécie de espiral crescente.

\section{Ao vivo: o tempo da performance}

Retomando o conceito de performance, devemos reiterar o aspecto de "irreversibilidade temporal" presente em ambas propostas. Donde a temporalidade do "ao vivo" que seria típica dessas poéticas vocais. No que se deve recuperar aquilo que Zumthor diz acerca do "tempo real", próprio da experiência poética (sua leitura, sua escuta ou audição), se pensada enquanto performance, mesmo que escrita em tempo diferido. A poesia que ressalta seu aspecto de performance, neste ponto, é aquela que provoca uma experiência temporal do fluxo do devir: a emergência do aqui-agora que passa, por um lado e seu caráter de sem retorno, de continuidade ininterrupta, por outro.

Aperghis se refere a esse "sem retorno possível", que é aquele do fluxo d'água, da queda de uma gota, na seguinte anotação, extraída de um de seus cadernos de notas:

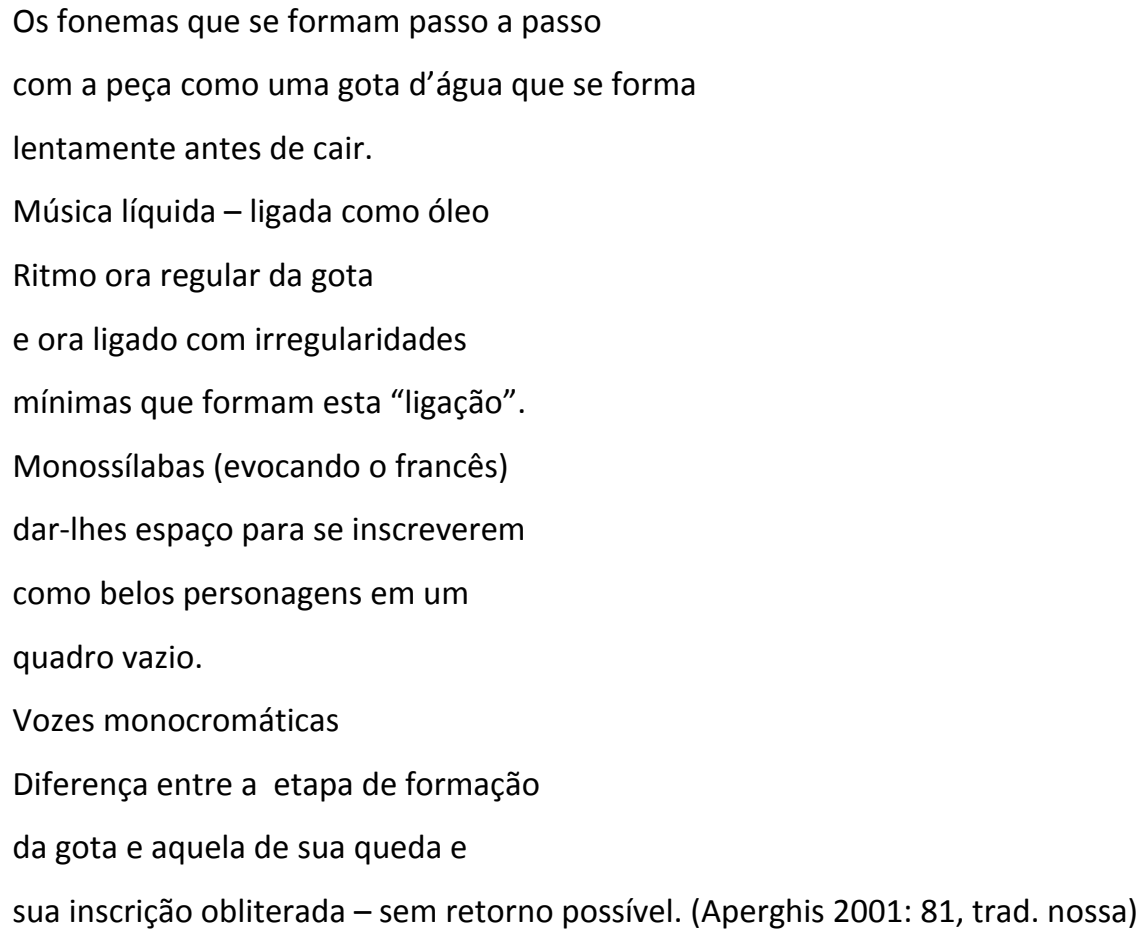


"Música líquida - ligada como óleo", composta pelas gotas que seriam os fonemas. Movimento irreversivel e incontido da queda d'água. A voz como fluxo líquido. Tal imagem é muito próxima àquela utilizada por Tarkos para descrever a sua vivência da língua enquanto fluxo. Para o autor, a língua é uma massa ou uma pasta, conforme o conceito criado por ele: "pâte-mot" (ou patmo), que traduziríamos por "pasta-palavra", tentando ecoar a sonoridade do francês. Tarkos imagina a linguagem como uma "pasta-palavra", uma massa elástica em que todas as palavras estão grudadas, juntas, aderidas. Com essa imagem, busca concretizar a ideia, cara a ele, de que não existe palavra isolada: as palavras só existem em grupo, só se dão coladas umas às outras: "não há palavras sós, as palavras estão em grupo, elas se misturam em um grupo, o que faz o elemento do sentido não é mais a palavra é o grupo de palavras fundidas" (Tarkos 1999: 29), lê-se em seu livro-manifesto Le signe =. O sentido é uma "pasta", portanto, que vai-se fazendo e se modificando na medida em que a moldamos, ao falar, em tempo real:

La liste des mots qu'il faut fusionnée donne une pâte molle. D'où le fait que tout ce que l'on dit a un sens de pâte, a une pâte de sens. Prend la forme d'une pâte. Après, la pâte peut se présenter dans n'importe quel sens, se renverser, se retourner, faire une boucle, faire des bouclettes, elle a toujours un sens, elle ne se déforme pas, puisqu'elle est une pâte elle peut prendre toutes les formes elle n'en reste pas moins sensée pleine de sens de ce qu'on dit, on peut la tirer et la tirer encore, l'allonger de beaucoup comme elle est élastique elle ne se casse pas [...] (idem: 31-32)

[A lista de palavras que é preciso fundir resulta em uma pasta cremosa. Donde o fato de que tudo o que dizemos tem um sentido de pasta, tem uma pasta de sentido. Toma a forma de uma pasta. Depois a pasta pode se apresentar em não importa qual sentido, se inverter, se revirar, fazer uma argola, fazer argolinhas, ela tem sempre um sentido, ela não se deforma, pois ela é uma pasta ela pode tomar todas as formas ela não fica menos sensata cheia de sentido daquilo que dizemos, podemos esticá-la e esticá-la ainda, alongá-la bastante como ela é elástica ela não se quebra [...] (trad. nossa).]

A consistência da pasta-palavra pode ser cremosa, há certa viscosidade nela, certa aderência, textura grudenta, elástica. Essa é a continuidade da fala, imaginada como pasta ou um purê (como dirá em outro texto), ela não se desagrega, não pulveriza, dá-se ligada. A imagem da pasta-palavra materializa a continuidade, sem cortes e irreversível, do tempo vocal. Tarkos refere-se em diversos momentos à experiência do fluxo, que pode ser 
expresso, como no texto visto anteriormente, em um "fluxo" de algo que não é definido, ou no fluxo da fumaça que sai do cigarro, do melado de uma compota ou, ainda, do contínuo da voz que fala. Nessa experiência está em jogo, para ele, a continuidade ininterrupta e sem volta da fala e, junto dela, a do próprio tempo, do devir: "Estamos na continuidade da fala, na continuidade do tempo. Então temos também a nostalgia contínua", diz em uma entrevista (Tarkos 2008: 366). A experiência da voz é colocada por Tarkos como algo vital, "cura-se falando", cura-se fazendo rondós com as palavras, colocando-as em ciranda:

Cela ne tient qu'à ma voix, en un temps mort pendant tout un temps mort, je parle, c'est ma voix qui est ma maladie, c'est ma voix qui est malade, tout ce que ma voix a parlé dans le temps rond, fini, mes paroles, le déversement de mes paroles est toute ma maladie, la rondeur de ma voix, la rondeur de tout ce que j'ai dit, tout ce que j'ai dit s'arrondit et s'enroule et s'enferme, est et est ma maladie qu'il faut soigner, que je suis venu soigner, on soignera en parlant, on soignera en faisant un rond de parole dans un temps mort, en faisant une rondeur d'un groupe de parole en un temps donné, ce sera tout, ce sera ma maladie et mon soin. [...] (Tarkos $2001: 48$ )

[Isso só depende da minha voz, em um tempo morto durante todo um tempo morto, eu falo, é minha voz que é minha doença, é minha voz que é doente, tudo o que minha voz falou no tempo circular, finito, minhas palavras, o escoamento das minhas palavras é toda minha doença, a curvatura da minha voz, a curvatura de tudo o que eu disse, tudo que eu disse se curva e se enrola e se fecha, é e é minha doença que é preciso curar, que eu vim curar, cura-se falando, cura-se fazendo um círculo de fala em um tempo morto, fazendo uma curvatura em um grupo de fala em um tempo dado, isso será tudo, isso será minha doença e minha cura. [...] (Trad. nossa).]

A referência aqui é explícita à doença que o acometeu o ainda jovem, a descoberta de um tumor no cérebro que o debilitou e o levou cedo, aos 41 anos de idade. Tarkos chega a mencionar que muito de seu modo de compor teria ligação com uma necessidade imposta pela doença: a falta de memória, que o obrigava a retomar palavras, e falar em ciclos curtos de tempo. O que poderia ser um recurso nascido também da prática das performances/ improvisações, porém, faz-se fortemente presente nos textos feitos especificamente para o suporte livro. Em Mil platôs, Deleuze e Guattari referem-se à distinção feita pela neurologia entre dois tipos de memória: a longa e a curta, para nelas destacar uma diferença não somente quantitativa. A memória longa seria aquela da escrita, ou do tipo de memória que a 
escrita permitiu ao homem, que seria para eles também a longa memória pressuposta nos modelos estabelecidos (eles dirão "arborificados", hierarquizados, centralizados) da língua escrita. Já a memória curta (de menos de um minuto) seria aquela típica da fala, composta de desvios, lapsos, saltos e insights. Uma vez que, na escuta de uma fala, não podemos voltar atrás e reouvir o que foi dito, o discurso oral é este que trabalha com reiterações, retomadas, isto é, ciclos menores; ele conta com o esquecimento e com as associações momentâneas, inesperadas, as irrupções e o engajamento do ouvinte nos ciclos criados. De modo que o ato de retomar palavras, frases, ideias, é típico da comunicação oral, que opera em "tempo real" e precisa acontecer na escuta do interlocutor, diante dele, criando com ele um espaço de escuta.

Escrever com a memória curta seria assim, para Deleuze e Guattari, justamente provocar uma escrita oralizada, baseada em "uma memória curta ou uma antimemória", escrita que "compreende o esquecimento como processo" (Deleuze/Guattari 1980: 24). A noção de uma escrita que se apoia no esquecimento é, portanto, central para o efeito de vocalidade.

Em Tarkos, a escrita se contamina dos gestos da fala, em que as repetições servem de apoios para a continuidade do fluxo. As palavras muitas vezes são retomadas em lugar dos brancos de memória, e servem como gancho para que o fluxo não seja estancado. Daí ser o tempo irreversível em Tarkos efeito desse mecanismo interno a seu envelope sonoro que denominamos por um fluxo de continuidade em que é a própria prontidão muscular da boca que fala quem determina qual o próximo passo imediato a ser dado: qualquer outro caminho seria uma quebra e irreversível. A repetição vem em função de promover o fluxo e nos colocar nesse tempo contínuo de uma fala obsessiva e desenfreada.

Em Aperghis, as repetições entram, ao contrário, em prol de provocar um fluxo truncado. Aliadas aos acréscimos paulatinos de termos, tal como vimos acima, truncando e retomando algum mote central, que ele faz proliferar. A partir de uma frase simples, que também pode ser cotidiana, ele remonta a frase a partir de sua primeira ou última palavra. Um dos textos da peça Machinations, espécie de metalinguagem do próprio processo de criação de Aperghis, apresenta um movimento que é presente em alguns de seus poemas, o acréscimo paulatino, por tropeções e repetições de palavras: 
Ses muscles

Ses muscles ses

Ses muscles ses muscles

Ses muscles ses muscles donnent

Ses muscles ses muscles donnent ses

Ses muscles ses muscles donnent ses muscles

Ses muscles ses muscles donnent ses muscles donnent

Ses muscles ses muscles donnent ses muscles donnent un

Ses muscles ses muscles donnent ses muscles donnent un ses

Ses muscles ses muscles donnent ses muscles donnent un ses muscles

Ses muscles ses muscles donnent ses muscles donnent un ses muscles donnent

Ses muscles ses muscles donnent ses muscles donnent un ses muscles donnent un geste

Ses muscles ses muscles donnent ses muscles donnent un ses muscles donnent un geste ses

Ses muscles ses muscles donnent ses muscles donnent un ses muscles donnent un geste ses muscles

Ses muscles ses muscles donnent ses muscles donnent un ses muscles donnent un geste ses muscles donnent

Ses muscles ses muscles donnent ses muscles donnent un ses muscles donnent un geste ses muscles donnent un Ses muscles ses muscles donnent ses muscles donnent un ses muscles donnent un geste ses muscles donnent un geste Ses muscles ses muscles donnent ses muscles donnent un ses muscles donnent un geste ses muscles donnent un geste clair. (Aperghis 2001: 56)

Aos poucos, por gaguejamentos, vai-se formando a frase mote: "ses muscles donnent un geste clair" (algo como "seus músculos dão um gesto claro"). Músculos faciais, guturais, gestos da boca, da língua e das palavras, uma linguagem sobretudo corporal, física, gestual. Esse gesto, trazido no fluxo truncado de Aperghis, liga-se bem à imagem trazida por ele da gota d'água que se forma lentamente antes de cair, criando as diferentes velocidades do percurso de uma gota que cai. Como no caso da gota, há uma tendência clara desse gesto, dessa velocidade: ela cresce, se acelera, paulatinamente. Vale notar que ela possui um sentido mais nítido - e uma regularidade temporal maior - do que aquele que veremos no caso de Tarkos. Aqui a ramificação não foi construída em tempo real, como o será em Tarkos, do qual muitos poemas são registros das improvisações em que eles nasceram, mas será expressa em tempo real através do registro sempre em uma forma de partitura que demonstra o caminho de sua construção. Há um trabalho muito interessante, imagético, nas partituras de Aperghis, na busca pela notação desses seus gestos de fala. O texto, ao ser realizado, refaz esse tempo do passo a passo, a sensação de que o fluxo de palavras se presentifica "ao vivo", expondo-nos ao seu processo. 
Já Tarkos trabalhará uma temporalidade que, ainda que também nascida da repetição, se dá a partir de diversos núcleos, sem a ênfase em uma tendência dominante. Nesse sentido, é como se houvesse em seus envelopes sonoros algo de uma imprevisibilidade maior e de uma convivência de ciclos heterogêneos. Como balizas de suas improvisações, Tarkos retoma palavras nucleares e as faz proliferar como se estriasse o tempo liso da improvisação com recorrentes pontos generativos. Núcleos ou centros provisórios que vão se deslocando e também vão se substituindo. Entretanto, o mecanismo é outro, e tem como efeito envelopes de temporalidades mais fluidas, em que os pontos de proliferação não atuam como pontos de corte, como em Aperghis, mas sim como pontos de deslize para novas ramificações:

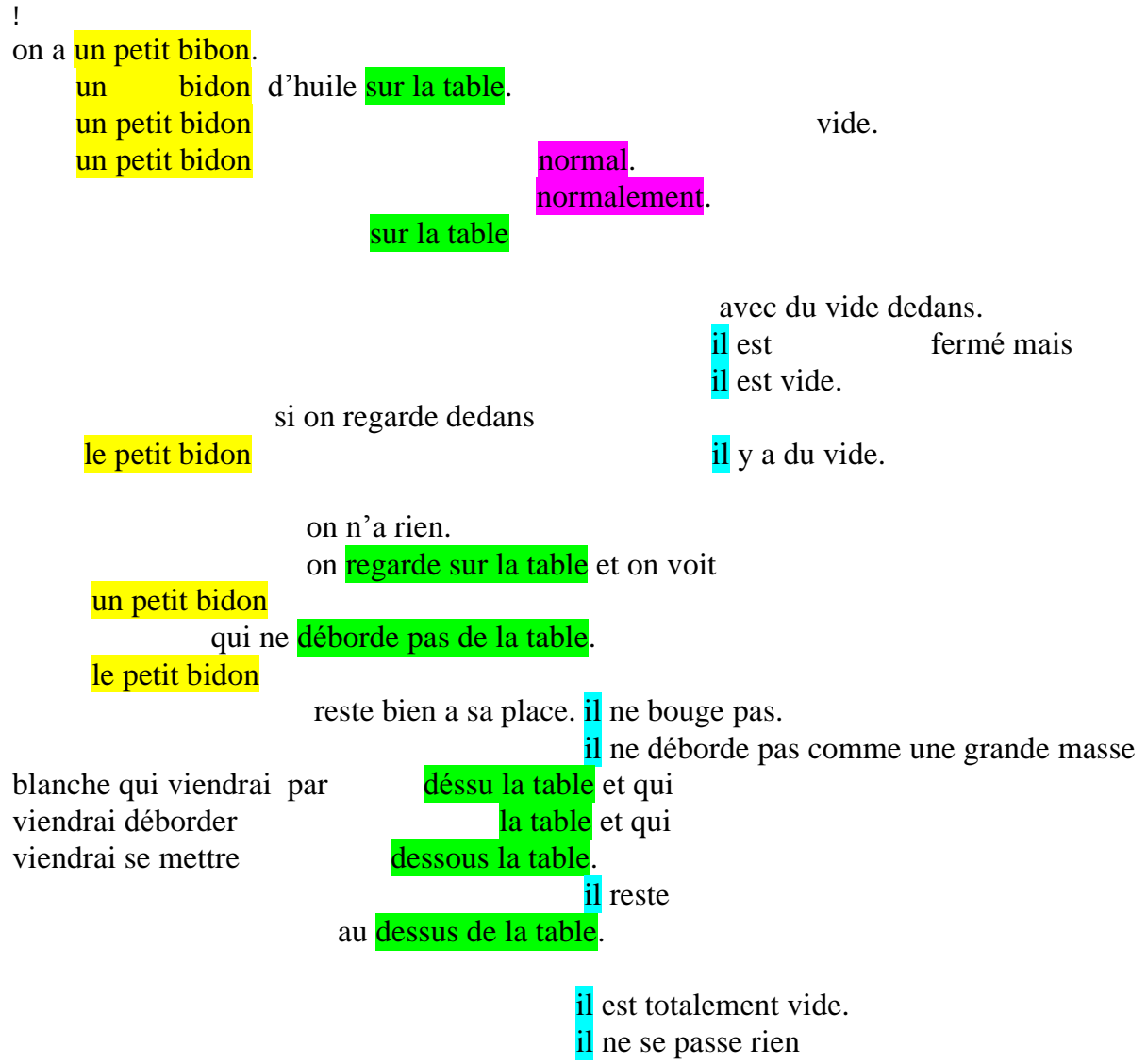

il est totalement vide.

il ne se passe rien

(Tarkos 2014: 453, grifos e diagramação nossos)

"Petit bidon" (pequena lata ou galão, de óleo), do qual traz-se aqui o trecho inicial, é um dos poemas que nasceram de performances que Tarkos realizava e, muitas vezes, como 
no presente caso, não chegava a anotar o texto que havia nascido ali. Performance, para ele, era sinônimo de improvisação, vemos em anotação sua que remete, justamente a "Petit bidon": "uma performance é uma improvisação/ coloco-me ali e falo/ uma improvisação se faz/ tal o petit bidon, que se deu no beaubourg, gravado nos estúdios do beaubourg [...]" (idem: 95). O poema foi performado em 1995 e, antes desse livro póstumo L'Enregistré (2014) que reúne textos inéditos, transcrições e dois CDs com áudios, só podia ser ouvido no áudio que restou da performance. A notação do poema acima (que não pertence à sua publicação póstuma), em colunas e com destaques, tem como objetivo expressar o ritmo que nasce do convívio das diversas repetições presentes. Ritmo resultante da irregularidade desses vários eixos, que parecem servir como breves apoios a partir dos quais o fluxo vocal escorre. Mesmo que não escutemos a gravação, em nossa leitura uma voz, com sua maneira de falar, se faz ouvir, conduzindo-nos por aquilo que Prigent dizia acerca de um mergulho no fluxo da elocução, conforme já ressaltado.

Os caminhos com que Aperghis e Tarkos imaginam suas máquinas de fala desenham possibilidades múltiplas de se trabalhar a vocalidade no texto e, com ela, o tempo real da performance. Mas em ambos podemos falar em um devir-voz da escrita, decorrente de uma operação sobre a vivência da temporalidade na leitura. Assim como Deleuze observa acerca das escritas "gaguejantes" de Charles Péguy, Samuel Beckett ou Ghérasim Luca, no ensaio de Crítica e clínica já citado, trata-se aqui de uma escrita arrastada pelo fluxo da voz que fala. 0 trabalho com ciclos breves - que observamos ser realizado de formas específicas em ambos autores -, em uma escrita toda feita de retomadas e ecos internos, provoca um outro tempo em nossa leitura. O tempo da memória curta do oral, como vimos em relação a Tarkos, ao evocarmos a perda de memória e seu papel na construção de uma escrita do tempo real da escuta. Tempo mais do esquecimento do que da memória, chamando-nos para uma presença no aqui-agora da performance.

É neste sentido que a "maquinação" de Aperghis desmonta palavras ou frases para recombiná-las em um fluxo contínuo, de cortes, em que a tendência que em geral se faz mais explícita é aquela na qual, por fim, a frase acaba sendo remontada - próxima ao mecanismo do poema já citado de Ghérasim Luca em que, por meio de tropeços, gagueiras e desmontagens, lentamente, a frase-chave acaba sendo composta (no caso: "Je t'aime 
passionnément", "te amo apaixonadamente"). Enquanto a "pasta-palavra" de Tarkos opera em uma dinâmica oposta: a de nascer sempre de aglutinações, que não são desfeitas e das quais os não-sensos podem surgir a cada momento, desfazendo a aparente banalidade da frase de origem. A frase nasce aglutinada e não se desmonta: as frases nascem já com suas palavras emendadas umas nas outras por hábitos de fala, por proximidade de envelopes sob ação de hábitos, tiques, manias de fala... uma palavra puxa outra, não por sua sonoridade isolada, mas sobretudo por seu envelope, por seu contorno de energia, de movimentos faciais, de modos de respiração implicados em cada palavra.

Na poesia de Aperghis, ou em suas partituras, a fala está presente mas transtornada, deformada por combinatórias quase impossíveis de serem pronunciadas sem um tropeção, enquanto em Tarkos o caminho é o inverso, é como se as palavras se encontrassem naturalmente pela predisposição muscular, recorrência corporal. Visto assim, podemos observar que Tarkos como Aperghis, e os dois em uma conversa direta com a obra de Samuel Beckett, trabalham naquele lugar em que sintaxe e palavras compõem dois sistemas independentes, que quase não conversam entre si. E em que o fluxo da voz, seu escoamento, desfaz a linguagem enquanto código e significação para encontrar, para aquém ou além, uma potência do corpo em seu movimento e, quando não, em seu silêncio. 


\section{Notas}

\footnotetext{
${ }^{1}$ Neste livro, Caisses, os poemas são todos diagramados de modo que as manchas de texto formem caixas, de fato.

2 Trata-se do artigo nosso, também em coautoria, "Música e voz para além do som", do qual destacamos o trecho:
}

É este aspecto comum à composição musical e à composição literária que chamamos aqui de a musicalidade possível de um texto, e por conseguinte sua vocalidade: a voz não como um objeto sonoro, ou como instrumento capaz de produzir objetos sonoros, mas a voz como máquina que produz envelopes sonoros que podem tanto ser decompostos quanto recombinados, ora compondo novos envelopes, ora distinguindo envelopes e os separando, os distanciando. Cujos objetos se destacam tanto pelos envelopes que desenham, pelas curvas sonoras que desenham, quanto pelas cadeias de significados que disparam, mas que não se reduzem em nenhum momento à sua sonoridade. (Ferraz/Malufe 2014: 163)

${ }^{3}$ O que é especialmente relevante no caso de Aperghis, com seus espetáculos multimidiáticos, em que articulam-se à palavra e aos poemas, as composições musicais, os sons eletrônicos e de instrumentos e, ainda, imagens projetadas e as visões dos corpos dos atores e instrumentistas. Daí nossa ressalva: concentramo-nos aqui na potência de performance da escrita, propomo-nos a analisar traços presentes nos textos desses autores.

${ }^{4}$ Vale citar aqui o trabalho pioneiro do poeta a escritor André Spire (1986) e a noção de prazer muscular associado ao prazer poético: a poesia como uma "dança bucal”, ou ainda, a ideia de que é "a boca que escolhe" as palavras e seus encadeamentos.

${ }^{5} \mathrm{O}$ trecho completo: "Si la langue se confond avec la parole, c'est seulement avec une parole très spéciale, parole poétique qui effectue toute la puissance de bifurcation et de variation, d'hétérogenèse et de modulation propre à la langue." (Deleuze 1993: 136-137)

6 "Diseuses", traduzível talvez por "dizedoras", é como Aperghis chama as atrizes, instrumentistas e cantoras que falam seus textos em Machinations, ou seja, "dizem-nos" - em vez de interpretá-los, declamá-los ou cantálos: “As 'diseuses' não fazem outra coisa além de 'dizer' os fonemas" (Aperghis 2001: 70). 


\section{Bibliografia}

Aperghis, Georges (1982), Récitations - pour voix seule (1977-1978). Paris, Ed. Salabert.

-- (2001), Machinations, Paris, L’Harmattan/Ircam.

-- (2004), Zig-Bang, Paris, P.O.L.

Deleuze, Gilles (1993), Critique et clinique, Paris, Minuit.

Deleuze, Gilles / Félix Guattari (1980), Mille plateaux - Capitalisme et schizophrénie 2, Paris, Les Editions de Minuit.

Ferraz, Silvio / Malufe, Annita Costa (2014), "Música e voz, para além do som", Literatura e Sociedade, Dossiê "Voz", n. 19, USP, 149-167.

Spire, André (1986), Plaisir poétique et plaisir musculaire, Paris, José Corti [1949].

Tarkos, Christophe (1995), Morceaux choisis, Les Contemporains Favoris, n. 7, Paris, Les Contemporains.

-- (1998), Caisses, Paris, P.O.L.

-- (1999), Le Signe =, Paris, P.O.L.

-- (2001), Anachronisme, Paris, P.O.L.

-- (2008), Écrits poétiques, Paris, P.O.L.

-- (2014), L'Enregistré - performances / improvisations / lectures, Paris , P.O.L

Zumthor, Paul (1997), Introdução à poesia oral, tradução de Jerusa Pires Ferreira et all, São Paulo, Hucitec.

-- (2005), Escritura e nomadismo, tradução de Jerusa Pires Ferreira e Sonia Queiroz, Cotia: Ateliê Editorial. 
Annita Costa Malufe é Doutora em Teoria e História Literária pela Unicamp, é pesquisadora PQ2 do CNPq, com projeto sobre ressonâncias de Samuel Beckett em poéticas contemporâneas. É autora de Poéticas da imanência: Ana Cristina Cesar e Marcos Siscar (7Letras/ Fapesp, 2011), além de seis livros de poemas. Realiza performances de leitura de poesia desde 2004 com o compositor Silvio Ferraz, com quem já publicou alguns artigos centrados nas relações entre poesia, música e performance. Fez duas pesquisas de pósdoutorado: na PUC-SP, com Peter Pál Pelbart, sobre relações entre as obras de Gilles Deleuze e Beckett; e na USP, sobre Beckett e Tarkos, com Fábio de Souza Andrade. É professora do programa de pós-graduação (mestrado e doutorado) da PUC-SP em Literatura e Crítica Literária.

Silvio Ferraz é Doutor em Comunicação e Semiótica pela PUC/SP, Livre Docente pela UNICAMP e Titular do curso de composição musical do Depto. de Música da USP. É compositor, autor de Música e Repetição: aspectos da questão da diferença na música contemporânea (EDUC/ Fapesp, 1997), do Livro das Sonoridades (7Letras/ Fapesp, 2004) e organizador de Notas-Atos-Gestos (7Letras/ Fapesp, 2007). Desde seus primeiros estudos acadêmicos, nos anos 1980, quando participou da segunda Anppom, tem se dedicado a compreender a pesquisa acadêmica sempre articulando estudos conceituais e a prática composicional. É pesquisador da FAPESP e CNPQ. 